\title{
Análise Numérica das Ações do Vento em Edifícios com Cobertura de Vão Múltiplos em Arco
}

\section{Pedro R. Campana, Cilmar D. Baságlia}

\section{Resumo}

A norma brasileira que prescreve os critérios e os procedimentos de cálculo para determinar as ações devido ao vento nas estruturas é a NBR 6123 (ABNT NBR 6123:1988) - Forças Devidas ao Vento em Edificações. Apesar da NBR 6123:1988 prescrever os coeficientes de pressão para telhados múltiplos com uma água vertical e para telhados múltiplos com duas águas, simétricos e assimétricos, de tramos iguais, nenhum procedimento é fornecido para telhados múltiplos em forma de arco. Esta pesquisa consiste em obter numericamente os coeficientes de pressão para coberturas em arco cuja geometria não está contemplada na norma.

\section{Palavras-chave:}

ação do vento, fluidodinâmica computacional, cobertura em arco

\section{Introdução}

Os efeitos de vizinhança entre edifícios, estudados por Negri (2017) e Takano (2019), possuem um caráter intrinsicamente não linear e estão presentes em muitas interações fluído-estrutura.

Por meio de modelagens em volumes finitos no software comercial ANSYS-CFX, foi analisada a ação do vento em galpões com $20 \mathrm{~m}$ de largura, $50 \mathrm{~m}$ de comprimento e paredes de $5 \mathrm{~m}$ de altura - em particular, foram estudados galpões:

i. em arco simples, cujas dimensões estão prescritas na NBR 6123:1988, a fim de validação do modelo numérico; ii. em arco simples, porém exibindo dimensões que não estão contempladas na NBR 6123:1988;

iii. em dois vãos em arco, cuja geometria não está prescrita na NBR 6123:1988.

\section{Resultados e Discussão}

A Tabela 1 apresenta uma comparação entre os coeficientes de pressão prescritos pela NBR 6123:1988 e os obtidos numericamente, para um vento incidindo a $0^{\circ}$ em um galpão com arco simples, cujas dimensões estão abrangidas pela norma (ver Figura 1).

Tabela 1. Coeficiente de pressão do vento a 0 ㅇ conforme os trechos divididos pela norma.

\begin{tabular}{|c|c|c|c|c|}
\cline { 2 - 5 } \multicolumn{1}{c|}{} & $\mathrm{A} 1+\mathrm{A} 2$ & $\mathrm{~B}$ & $\mathrm{C}$ & $\mathrm{D} 1+\mathrm{D} 2$ \\
\hline NBR 6123 & $-0,8$ & $-0,6$ & $-0,3$ & $-0,2$ \\
\hline $\begin{array}{c}\text { ANSYS- } \\
\text { CFX }\end{array}$ & $-0,8$ & $-0,4$ & $-0,1$ & $-0,2$ \\
\hline
\end{tabular}

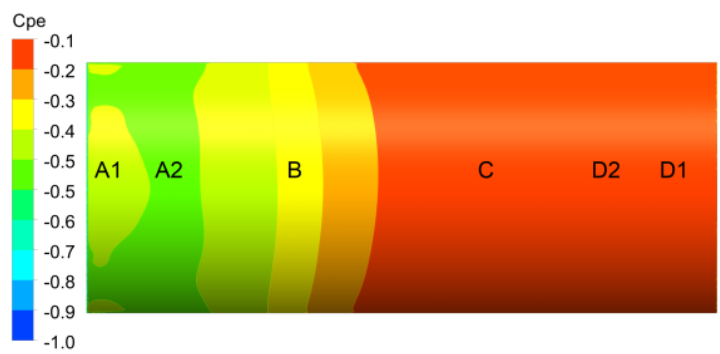

Figura 1. Coeficiente de pressão do vento a $0^{\circ}$, incidindo na face a esquerda.

Enquanto que a Figura 2 apresenta os coeficientes de pressão obtidos numericamente para um edifício com cobertura em arco simples cujas dimensões não estão prescritas na NBR 6123:1988, a Figura 3 apresenta os coeficientes de pressão para cobertura com dois arcos.

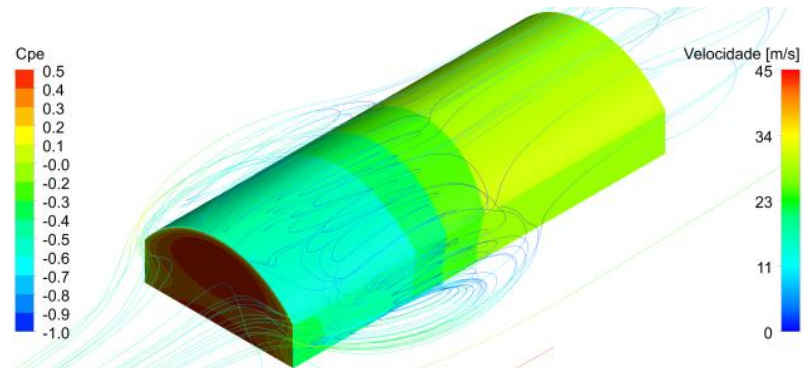

Figura 2. Coeficiente de pressão e linhas de corrente do vento a 0 - para o modelo em arco simples.

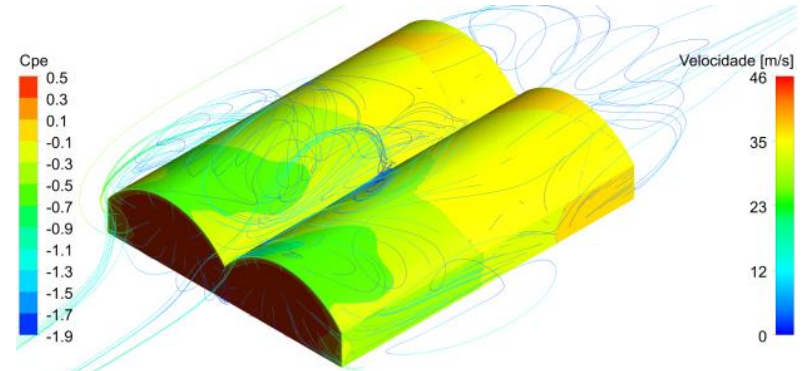

Figura 3. Coeficiente de pressão e linhas de corrente do vento a $0^{\circ}$ para 0 modelo de cobertura em arcos múltiplos.

\section{Conclusões}

O método de análise numérica se mostrou consistente em prever áreas de formação de vórtices e zonas de alta sucção. Os valores dos coeficientes de pressão, no entanto, ainda podem ser melhorados e mais pesquisa em otimização é necessário para melhorar a precisão e diminuir o custo computacional.

\footnotetext{
1 Associação Brasileira de Normas Técnicas, ABNT, NBR 6123. (1989) Forças devidas ao vento em edificações, Rio de Janeiro, 1989

2 Negri J.F.G. (2017). "Efeitos de vizinhança nas ações do vento em edifícios com cobertura em duas águas", Dissertação de Mestrado, Faculdade de Engenharia Civil, Arquitetura e Urbanismo, Universidade Estadual de Campinas (FEC-Unicamp).

3 Takano M.O. (2019). "Análise numérica das ações de vento em galpões com cobertura de vãos múltiplos em forma de arco", Dissertação de Mestrado, Faculdade de Engenharia Civil, Arquitetura e Urbanismo, Universidade Estadual de Campinas (FEC-Unicamp).
} 